EGU2020-5881

https://doi.org/10.5194/egusphere-egu2020-5881

EGU General Assembly 2020

(c) Author(s) 2020. This work is distributed under

the Creative Commons Attribution 4.0 License.

\title{
A global scale geospatially located landslide dam dataset
}

\author{
Hang $\mathbf{W} \mathbf{u}^{1}$, Mark Trigg ${ }^{1}$, and William Murphy ${ }^{2}$ \\ ${ }^{1}$ School of Civil Engineering, Faculty of Engineering and Physical Sciences, University of Leeds, UK \\ ${ }^{2}$ School of Earth and Environment, Faculty of Environment, University of Leeds, UK
}

Landslide dams are a common hazard reported in mountainous areas around the world, where the dams block the normal flow of the river and can cause catastrophic flooding downstream when the temporary dam subsequently fails. Most of the research that couples landslide dams and fluvial systems have been concentrated on a site-specific scale and thus little is known about where these hazards are clustered and how they connect to climate and geology. A detailed and comprehensive dataset of landslide dams is not currently available at the global scale, since most global landslide dam datasets contain very little precise spatial information, which makes it harder to explore and to analyze the impacts on floods by modelling over larger scales.

To narrow this data gap, we are developing a new global landslide dam dataset, recording: spatial coordinates, time information, dam materials, geomorphic characteristics of catchments, landslides, landslide dams and impounded lakes, and hydrographic characteristics of subsequent flood events and their consequent damage. This has been collated from bibliographic works in a number of languages. In the process of building the database we have encountered several obstacles including language barriers, indistinct naming standards, vague and patchy spatial information, and the diversity of data access in different countries. So far, we have data from over 700 individual events that have been synthesized into the same data format with consistent units and spatial references.

The spatial distribution of landslide dam shows hazard hot spot areas concentrated around mountainous areas. The number of landslide dams reported increases exponentially during the past 1000 years, with the highest peak in the last 20 years. This increase is most likely due to better records in more recent years. Some extreme large-scale events, including earthquakes, floods, typhoons and volcanic eruptions have contributed to other peaks in the record. Initial analysis of the data will be used to explore distribution differences of dimension data, such as height, length and volume, of landslide dams that are induced by different triggers, to explore the triggers effect on landslide dam formation.

The summary information of the dataset and the characteristic analysis result will be presented with a comparison to existing landslide dam datasets. A spatial distribution map of landslide dams and hazard hot spot areas will also be presented. This extensive global landslide dam dataset will allow researchers to understand the spatial distribution, geomorphic characteristics of landslide dams, and the connections among the dimensions of landslide sources, landslide dams, 
impounded lakes and upstream catchments. We will continue to develop this current landslide dam dataset and welcome feedback and additional datasets to supplement the database. Upon completion, the dataset will be made open access for wider research purposes and collaborations. 